\title{
Parlamentos y afuerinos en la frontera mapuche del río Bío-Bío (Chile), 1760-1772
}

\author{
Leonardo León \\ Universidad de Chile \\ lleonsolis@yahoo.es
}

\section{Resumen $^{1}$}

En este artículo se analiza la proliferación de renegados mestizos en los territorios fronterizos mapuches de la región del río Bío-Bío durante la segunda mitad del siglo XVIII y el desarrollo de la política de ordenamiento llevada a cabo conjuntamente por las autoridades tribales y monárquicas a través del sistema de parlamentos. Se examinan las actas de las reuniones realizadas durante las décadas de 1760 y 1770, y se las interpreta como la base de una modalidad de cogobierno, fenómeno inédito en la historia del continente. Se pone especial énfasis en la participación de las autoridades tribales en este proceso, como una forma de rescatar la acción política de sujetos considerados tradicionalmente como salvajes.

Palabras clave: CHILE, SIGLO XIX, MAPUCHE, PARLAMENTO, COGOBIERNO, TRATADO.

\begin{abstract}
This articles examines the increasing presence of mestizos outlaws in the Mapuche frontier in the region of Bío-Bío during the second half of the $18^{\text {th }}$ century, and the development of a joint policy of social ordering coordinated between Mapuche leaders and the monarchist authorities through the Parlamento system. To achieve these objectives, this article reviews the minutes of those meetings which took place during the decades of 1760 and 1770, and interprets its accords as the basis for an original system of cogobierno that was quite exceptional in the Continent. Special emphasis is put on the participation of tribal leaders throughout this process, as a means to rescue the political actions of subjects traditionally considered as savages.
\end{abstract}

Key words: CHILE, $18^{\mathrm{TH}}$ CENTURY, MAPUCHE, PARLAMENTO, COGOBIERNO, TREATY.

\footnotetext{
${ }^{1}$ Este trabajo se realizó con el apoyo financiero del Proyecto Fondecyt 1000121 "Tipos humanos y espacios de sociabilidad en la frontera mapuche de Argentina y Chile, 18001900". Mis agradecimientos a los licenciados Hugo Contreras y Claudio Palma por su colaboración profesional. Expreso mis disculpas a los lectores por el uso de palabras mapuches, pero un estudio sobre el mestizaje no podía evitar que se hiciera presente uno de los instrumentos más visibles de aquellos procesos profundos: el mestizaje de la palabra.
} 
Durante la segunda mitad del siglo XVIII, la frontera mapuche del río Bío-Bío registró un gradual deterioro en su gobernabilidad debido al incremento del bandidaje, el despliegue de la insubordinación de los peones y la creciente ola de violencia interpersonal que afectó esos distritos ${ }^{2}$. Sus protagonistas fueron los afuerinos, un segmento del mestizaje que eligió vivir al margen de la sociedad, fuese esta española o indígena. En efecto, durante un período en que las autoridades monárquicas del reino de Chile y los jefes tribales de la Araucania se esmeraron por reforzar su autoridad y los dispositivos de control social, los afuerinos reaccionaron contra estas políticas redoblando sus acciones transgresivas mientras se retiraban hacia las montañas en busca de un territorio donde sobrevivir y preservar, al mismo tiempo, su identidad. Desde allí, reprodujeron sus anárquicos modos de vida e intensificaron sus relaciones con el bajo pueblo y el "indianaje" Por sobre todo, los afuerinos se empeñaron en reproducir un modo de vida que trasladaba hacia el norte del río Bío-Bío las conductas hasta allí atribuidas al mundo tribal. Luchaban para ser vistos como hombres libres, pero tanto los hispano-criollos como los mapuches los trataron como tránsfugas o renegados.

El paisaje que sirvió de escenario a las andanzas de los afuerinos lo conformaron los corregimientos hispanos de Penco y Maule, la Isla de la Laja y los distritos de Rere y Puchacay. En la Araucania, en el territorio propiamente tribal, sus lances tocaron a las parcialidades de Angol, Malleco, Renaico y Mulchén y el país costero. En conjunto, esos territorios constituían la frontera propiamente tal; más que una línea de fuertes, ésta tomaba la semblanza de un espacio convertido en tierra de nadie. Allí se multiplicaron los rancheríos y las behetrías que escapaban de la tutela y la jurisdicción de las autoridades tradicionales, para levantarse como símbolos de la resistencia de los afuerinos y como eficaces guaridas de los malhechores que huían de la justicia. Como bien señaló Sergio Villalobos, las características más sobresalientes de esta región durante aquel período fueron "el

\footnotetext{
${ }^{2}$ Mario Góngora, "Vagabundaje y sociedad fronteriza en Chile (siglos XVI a XIX)", en Estudios de historia de las ideas y de historia social (Valparaíso: Universitarias del Valparaíso, 1980), 341-390; María Teresa Cobos, "La institución del juez de campo durante el siglo XVIII", Revista de Estudios Histórico-Jurídicos (Valparaíso, Chile), 5 (1980): 85-165; Gabriel Salazar, Labradores, peones y proletarios. Formación y crisis de la sociedad popular chilena (Santiago: Sur, 1985); E. Cavieres, "Sociedad rural y marginalidad social en Chile tradicional, 1750-1860", en Agricultura, trabajo y sociedad en América hispana, ed. Gonzalo Izquierdo (Santiago: Universidad de Chile, 1989), 91-105.

${ }^{3}$ Alejandra Araya, Ociosos, vagabundos y malentretenidos en Chile colonial (Santiago: Dirección de Bibliotecas, Archivos y Museos, 1999); David Weber, "Borbones y bárbaros. Centro y periferia en la reformulación de la política de España hacia los indígenas no sometidos", Anuario de Estudios Histórico Sociales (Tandil, Argentina), 13 (1998): 147171.
} 
choque esporádico, el tráfico, el crimen y el robo, el mestizaje y la transculturación"4. Descrita como una auténtica "bisagra" del reino, la frontera era precaria, defendida pobremente con los exiguos fondos del Real Situado e infiltrada por el comercio ilegal que promovía la soldadesca arraigada en esas tierras.

A mediados del siglo XVIII, el espectáculo que ofrecían los villorrios fronterizos estaba muy distante de la imagen pastoril que se podría tener de las aldeas sureñas. "En los días de fiesta por la tarde", observaron los miembros del sínodo de 1744 refiriéndose a las actividades de los peones de Concepción que se trasladaban desde sus rancheríos hacia las villas, "ocurren a las pulperías del pueblo, donde embriagados pierden con el corto jornal que destinan al vicio, los caballos,

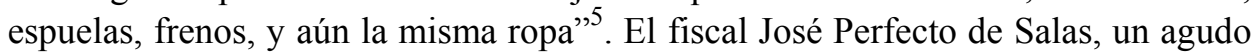
observador de los obstáculos que enfrentaba la política de fundación de poblaciones en Chile central, observó en 1750:

Después de haber mediado dos siglos de vida libre, con facultad de residir los moradores donde han querido, apenas se ha podido conseguir que una de las cuatro partes de ellos se sujeten a la vida civil $[\ldots]^{6}$.

Si así era descrita la vida de la plebe en los espacios dominados, ¿cómo era la que prosperaba en las numerosas behetrías que surgían más allá del control estatal y qué podían hacer las autoridades, monárquicas y tribales, para contener los desbordes y excesos que protagonizaban los afuerinos? Atendiendo a estos interrogantes, en este estudio se analiza la estrategia política implementada entre 1760 y 1772 por las autoridades españolas y mapuches para poner fin a la situación de caos social que creaban los afuerinos en la frontera ${ }^{7}$. Se plantea que durante esa

\footnotetext{
${ }^{4}$ Sergio Villalobos, "Tipos fronterizos en el ejército de Arauco", en Relaciones fronterizas en la Araucania, Sergio Villalobos y otros (Santiago: Universidad Católica de Chile, 1982), 175-221; Patricia Cerda-Hegerl, Fronteras del Sur. La región del Biobio y la Araucania chilena, 1604-1883 (Temuco: Universidad de la Frontera, 1996), 30.

5 "Primer Sínodo Diocesano [que] celebró el Iltmo. Señor Doctor Don Pedro Felipe de Azúa e Iturgoyen, del Consejo de $\mathrm{Su}$ majestad, Obispo de esta Santa Iglesia de la Concepción de Chile, 12 de octubre de 1744", citado por Carlos Oviedo Cavada, "La defensa del indio en el sínodo del obispo Azúa de 1744", Historia (Santiago), 17 (1982): 317.

${ }^{6}$ José Perfecto de Salas, "Informe sobre el Reino de Chile, 1750", en Ricardo Donoso, Un letrado del siglo XVIII. El Doctor José Perfecto de Salas (Buenos Aires: Universidad de Buenos Aires, 1963), 1:108.

${ }^{7}$ Los aspectos relacionados con la insubordinación mestiza durante el período previo a este estudio han sido examinados en Leonardo León, "Mestizos e insubordinación social en la frontera mapuche, 1700-1726", Estudios Coloniales (Santiago), 2 (2002): 207-280; "Evolución de la frontera pehuenche en La Laja y Bío-Bío: territorios, comercio y
} 
época se gestaron las condiciones políticas para que surgiera una modalidad excepcional de cogobierno de la frontera cuyo objetivo común consistió en ordenar las relaciones de coexistencia. De ese modo, tanto los representantes del monarca como los principales jefes mapuches perseguían eliminar los resquicios que aprovechaban los afuerinos para desplegar sus conductas insubordinadas. De su extirpación dependía, en gran parte, la consolidación del régimen de relaciones pacíficas que desde mediados del siglo XVII enmarcó los contactos hispanomapuches, y que después de varias décadas se había transformado en la base material del poder acumulado por los ulmenes (hombres ricos mapuches) y de las élites criollas regionales.

\section{La gestación de la crisis}

Por cuanto Narciso Enriques y Miguel Rey, quebrantando los tratados del parlamento y repetidos bandos que se han echado que prohíben la entrada a la tierra estos ilícitos comercios con los Yndios, fueron cogidos tierra dentro conchabando una recua de caballos por ponchos siendo hurtados, de lo que sigue el alboroto que estos causan a los yndios con sus novedades que los llevan, destruyendo a este vecindario y dándoles armas al enemigo $[\ldots]^{8}$.

Bajo estas acusaciones, que describen los perjuicios que creaban los afuerinos cuando comerciaban ilegalmente en las tierras tribales, el comandante de la plaza fronteriza de Arauco condenó en 1771 a Enriques y Rey a cuatro años de trabajos forzados, "a ración y sin sueldo", en la isla de Juan Fernández. Pero no fueron solamente sujetos plebeyos quienes transgredieron la ley. Apenas dos años antes, Laureano Bueno, comandante del fuerte de Santa Bárbara, fue acusado de tener

[...] frecuente comercio con los Yndios infieles internándoles por terceros personas no solo yeguas, sino también recuas de vino a conchabo de ponchos [...] está siempre comprando caballos hurtados a conocidos ladrones para sus conchabos en la tierra $[\ldots]^{9}$.

misiones, 1730-1760”, Revista de Ciencias Sociales (Valparaíso), 44 (1999): 409-475; "La herida me la dio en buena [...] El ordenamiento del espacio fronterizo mapuche, 17261760", Revista de Historia Social y de las Mentalidades (Santiago), 5 (2001): 129-166.

8 "Sentencia dictada por don Antonio Narciso de Santa María", Arauco, 26 de septiembre de 1771, Archivo Nacional -en adelante AN- (Santiago), Capitanía General, vol. 304, fol. 198.

9 "Declaración de don Fructuoso López, vecino de Santa Bárbara, ante el obispo Ángel Espiñeira", Concepción, 3 de enero de 1769, en "Criminales seguidos contra el teniente Don Laureano Bueno por cierta y ilícita amistad, y comersio con los Indios", ibídem, vol. 300, fol. 137. 
Las acusaciones contra Bueno no se remitían exclusivamente al conchavo ilícito.

Sabe por vos común y general -declaró otro testigo- que el referido Don Laureano, desde que entró de comandante a la dicha plaza de Santa Barbara tiene ilícita amistad escandalosa con la referida doña Feliziana Zapata, aun antes de que muriese Don Andrés del Alcázar su marido [...] y lo confirma la frecuencia del dicho comandante en casa de la susso dicha, así de día, como a escusadas horas de la noche [...].

Al decir de otro testigo, la mujer también había manifestado escaso recato de su clandestina relación con el comandante del fuerte afirmando, en más de una oportunidad, "que se le daba muy poco de que se dijese que estaba en ilícita amistad con el dicho Don Laureano, porque era buen mozo"10. Estas expresiones, escogidas entre centenares de testimonios similares que emergen de los archivos judiciales del período, dan cuenta de la complejidad que adquirió el quehacer cotidiano de los mestizos cuando decidían realizar sus acciones a espaldas del Estado. Se puede decir que estas acciones carecían de un plan, pero no se puede desconocer que tanto el desacato como la insubordinación debilitaban la institucionalidad y contribuían a la subversión del orden social.

Al otro lado del río Bío-Bío, los jefes tribales enfrentaron problemas similares. Así sucedió en 1736, cuando los werquenes (mensajeros) de la comunidad de Guachipen, a nombre de sus lonkos (jefes tribales) manifestaron que estaban dispuestos a solicitar al gobernador del reino que "ponga reparo a este desorden de entrar los Españoles con conchavos a sus tierras por cuya causa experimentan algunos agravios" $"$. Pero los mestizos transformados en afuerinos no se dedicaban solamente al robo o al comercio entre los mapuches. Otros, como Joseph Repucheta, actuaban como espías.

En esta villa había un mestizo -declaró un testigo en 1770- que comunicaba cuanto pasaba en esta dicha Plaza con el cacique Colgueman, su hijo Pellon, y los suyos y que este dicho mestizo vivía junto al convento, y que su traje o vestuario era de cabrón colorado, y calzado y que en premio de esta maldad tan execrable le habían pagado un poncho, una Chinilla o Gueñi $[\ldots]^{12}$.

\footnotetext{
10 "Declaración de Alejo Salazar", Concepción, 3 de enero de 1769, ibídem, fol. 139v.

11 "Declaración de Francisco Libnopañi y Manuel Millaguala", Yumbel, 12 de marzo de 1736, ibídem, vol. 48, fol. 398 v.

12 "Auto Cabeza de Proceso dictado por el gobernador de Santa Bárbara" [3 de agosto de 1770], ibídem, vol. 306, fol. 347. Gueñi: niño.
} 
Igualmente negativa fue la intervención de los afuerinos en la política interna de los butalmapus (provincias o distritos en que estaba subdividido el territorio mapuche), que generó las sangrientas guerras tribales, el pillaje y vandalismo que de tiempo en tiempo sacudieron la organización tribal ${ }^{13}$. El súbito ascenso de los capitanejos y toquis (jefes militares mapuches) apoyados por audaces afuerinos, fue el mejor signo del predominio que alcanzaban los forasteros en el complejo tejido de la sociedad mapuche. Bajo el imperio de la violencia desatada por ellos, afloraba el weichan (tiempo de guerra), sin que fuera posible sofocar sus funestas secuelas.

En esas circunstancias, tanto en Chile como en la Araucania, colapsaba el estado de derecho y sucumbían tanto la juridicidad monárquica como el admapu (derecho consuetudinario) mapuche. Poco importaba esto al afuerino, que vivía más allá de los cánones y normas de ambas sociedades. Sin ser español ni mapuche, resumía en su vida la arrogancia, el individualismo y la soberbia de sus progenitores históricos; para él, tanto los jefes tribales como los corregidores carecían de legitimidad para gobernarlos. Hijos de la violencia, su principal señor fue la lanza o el cuchillo. Así ocurrió con Juaniquillo, un indio amestizado del partido de Puchacay, que entró a un rancho en busca de su mujer:

[...] y anduvo alumbrando por todos los rincones, hasta que dio con su mujer que estaba borracha y dormida sobre sus faldas, estaba el indio Silvestre dormido y borracho, entonces dice que vio que a su mujer le dio con el tizón en la cabeza y al indio Silvestre le dio una puñalada y luego que se la dio se salió para afuera sin hablar palabra $[\ldots]^{14}$.

José Catrilab, uno de los testigos del drama, afirmó que todo había ocurrido después de un mingaco (cosecha comunitaria) y que por estar borracho "dice que se levantó y halló al indio Silvestre ya muerto y a la mujer del matador sentada en

13 Leonardo León, "La corona española y las guerras intestinas entre los indios de Araucania, Patagonia y las Pampas, 1760-1806", Nueva Historia (Londres), 5 (1982): 3167; Apogeo y ocaso del toqui Francisco Ayllapangui de Malleco, 1769-1776 (Santiago: Centro de Investigaciones Históricas Diego Barros Arana, 1999); Los señores de la cordillera y las pampas: los pehuenches de Malalhue, 1770-1800, $2^{\mathrm{a}}$ ed. (Santiago: Centro de Investigaciones Históricas Diego Barros Arana, 2005). Bibliografía adicional en Eugenio Alcamán, "Los mapuche-huilliche del futahuillimapu septentrional: expansión colonial, guerras internas y alianzas políticas (1750-1792)", Revista de Historia Indígena (Santiago), 2 (1997): 29-75; Juan F. Jiménez, "Guerras intertribales, guerras coloniales y conservación del poder entre los peguenches de Malargue: la jefatura de Ancán Amun (1779-1787)", manuscrito (Neuquén: Universidad del Comahue, 1997).

14 "Sumario para establecer el autor del homicidio del indio Silvestre Puchacay Trubunquén" [26 de agosto de 1751], AN (Santiago), Archivo Judicial de Puchacay, vol. 13 , pieza 10 , s. fol. 
el fuego muy borracha". La naturalidad con que se relatan hechos encubre algunos aspectos más profundos, tales como la presencia de varios peones mapuches en distritos de españoles y la ausencia de pudor y solidaridad que se vislumbra en la conducta de los protagonistas. Lo que más sobresale es que en la frontera se disolvían los antiguos lazos que antes unían, en sus respectivos mundos, a españoles y mapuches. Allí no solo estaba ausente el Estado, sino también el respeto y el sentido del honor que se derivaba de la pertenencia a un linaje.

Desde comienzos del siglo XVIII, la frontera mapuche se alzaba como un universo tosco e independiente, poblado por hombres y mujeres que rehusaban someterse a las autoridades. "La existencia despreocupada, el ocio, la pillería, el hurto", escribió Villalobos, "la jugarreta, el vivir engañando y tomando las cosas con humor, fueron modalidades de la vida diaria" ${ }^{\prime 15}$.

A mediados de la centuria, el deterioro de los dispositivos de control se hizo más patente. La población de Concepción, que en 1720 no subía de 11.000 personas, creció a más de 50.000 habitantes a mediados de la centuria. De estos datos no es posible calcular la población afuerina, cuya condición marginal la excluía de los empadronamientos, pero es innegable que más de un siglo de mestizaje había procreado a un nuevo sujeto histórico que no estaba dispuesto a seguir el camino de fidelidad y cooperación de sus antepasados -europeos o mapuches- y que, además, mostraba una firme determinación para forjar su propio futuro. Como los llaneros del Apure y los gauchos de las Pampas, el afuerino, con sus rasgos de hombre rudo, no era tan solo temido porque provenía de distritos lejanos, sino porque en su rostro se leía la historia del sujeto criado fuera del sistema ${ }^{16}$. Socialmente, era el parangón humano del ganado cimarrón que trashumaba por las pampas y cordilleras, un epítome del bárbaro y del salvaje. ¿Quién se atrevería a amansarlo, domesticarlo y hacerlo socialmente útil?

Los afuerinos desarrollaron su existencia más allá del tutelaje de hacendados y lonkos, buscando el monte, la quebrada o el páramo para instalar sus ranchos $\mathrm{y}$, desde allí, sembrar el terror sobre las apacibles campiñas. Con excepción de los rehues y las villas de españoles, el resto del territorio era su terruño, su patria chica, cuyos caminos y derroteros solamente él conocía. Como miembro de una masa vagabunda de hombres-sin-tierra, que cabalgaban en busca de la mujer, el rebaño, los bienes o la propiedad de los demás, su mera presencia causaba temor entre peones y hacendados ${ }^{17}$. ¿Podría ser de otro modo en una región que, por

\footnotetext{
15 Sergio Villalobos, Vida fronteriza en la Araucania. El mito de la Guerra de Arauco (Santiago: Andrés Bello, 1995), 209.

${ }^{16}$ Carlos A. Mayo, edit., Vivir en la frontera. La casa, la dieta, la pulpería, la escuela (17701870) (Buenos Aires: Biblos, 2000); David Weber y Jane M. Rausch, eds., Where cultures meet. Frontiers in Latin American History (Washington: Scholarly Resources, 1994).

${ }^{17}$ Salazar, Labradores, peones y proletarios, 40.
} 
siglos, fue uno de los presidios más populosos y temidos de América y donde, de tiempo en tiempo, se hacía sentir de nuevo el viento huracanado del Flandes indiano?

Durante el siglo XVII -señaló Hugo Contreras- la frontera hispano mapuche del río Bío-Bío vio arribar enganchados como soldados a una serie de sujetos de los más diversos orígenes étnicos y geográficos, muchos de los cuales eran hombres ociosos, ladrones o vagabundos $[\ldots]^{18}$.

En realidad, tenía razón Mario Góngora al postular que la criminalidad fronteriza fue el fruto de la suma de "vagabundaje + frontera de guerra + mestizaje", pues el rasgo más peculiar del acontecer cotidiano en las regiones colindantes al río BíoBío fue la presencia de un sujeto social que creció más allá de toda norma. Por supuesto, no todos los mestizos se comportaban de esa manera, pero los que lo hacían -y fueron reconocidos por el resto de la población por sus trazas de afuerinos- fueron más que suficientes para imponerle un tono de violencia y trasgresión al acontecer cotidiano. Solamente resta agregar a esta fórmula el surgimiento del nuevo paradigma antiautoridad que desarrollaron los afuerinos y la crónica debilidad institucional -tanto monárquica como tribal- que estos sujetos explotron sin cesar. Mestizos y fronteras existieron a lo largo y ancho de las Américas, pero en pocos lugares se combinaron estos elementos de un modo tan preciso como en la frontera del Bío-Bío. Allí, el afuerino, hijo ilegítimo de la Guerra de Arauco, educado en el fragor de cordilleras y selvas, amparado por los "indios libres" y perseguido por sus primos blancos, fue evolucionando hasta convertirse en un sujeto histórico que no tendría parangón en el resto del continente. Fue el fruto de una historia que otros países no conocieron.

La transición racial y social, que también se registró en otras regiones del subcontinente, pudo haber pasado más o menos desapercibida en Chile, de no haberse manifestado como una explosión de violencia y desacato popular ${ }^{19}$. Enfrentados a una creciente ola de criminalidad, las autoridades monárquicas reforzaron desde mediados del siglo XVIII los mecanismos de control de la población, aceleraron su política fundacional de villas, ejercieron una mayor vigilancia sobre las autoridades subalternas y procuraron, a través de bandos de buen gobierno, extender a las campañas las severas reglamentaciones que se implantaban en las ciudades para reprimir las manifestaciones de sociabilidad de la plebe ${ }^{20}$. Se acentuaron también

${ }^{18}$ Hugo Contreras, "La soldadesca en la frontera mapuche del Bío-Bío durante el siglo XVI, 1600-1700” (Tesis de Maestría, Universidad de Chile, Santiago, 2001), 124.

${ }^{19}$ Leonardo León, "Historia social de la frontera mapuche en Chile y el Río de la Plata, 1700-1800”, manuscrito (Santiago, Universidad de Chile, 2005).

${ }^{20}$ Santiago Lorenzo, Origen de las ciudades chilenas. Las fundaciones del siglo XVIII (Santiago: Andrés Bello, 1983); Cobos, "La institución del juez", 85-165. 
las formas de castigo que buscaban amedrentar al resto de la población -tales como los azotes, la exposición vejatoria de los reos en grillos y cepos, la ejecución con descuartizamiento en la Plaza de Armas y la exhibición de sus restos mutilados en las encrucijadas de caminos-y además se multiplicaron las sentencias judiciales que incluían trabajos forzados y destierros a las plazas de Valdivia o Juan Fernández ${ }^{21}$.

Al sur del río Bío-Bío, los jefes tribales comenzaron a concentrar mayor poder en sus manos y debilitaron la base social de los capitanes de guerra, principales protagonistas de los robos y salteos que afectaban a las villas y rehues circunvecinos. Simultáneamente, restaron autoridad y representación a los toquis (jefes de guerra) para atenuar su influencia sobre el resto de la sociedad y, por sobre todo, monopolizaron en sus manos el trato comercial, político y diplomático que se mantenía con los españoles. Convertidos en ulmenes, hombres ricos, los jefes tribales dieron los primeros pasos hacia el señorialismo que, en términos políticos, generaba el anhelado interlocutor que por siglos buscaron los hispanocriollos. Lo que no pudieron precaver los lonkos fue el recrudecimiento de las guerras internas, toda vez que los cambios estructurales que afectaron a la sociedad mapuche durante el siglo XVIII desataron inevitables contradicciones de intereses entre los diversos segmentos sociales y étnicos. La guerra intestina significó un profundo quiebre de la cohesión tribal.

No obstante, a pesar de los desgarros que provocaban las confrontaciones intertribales, los lonkos no perdieron de vista un objetivo principal en su gestión: ordenar la vida cotidiana para reprimir a los afuerinos. Tanto para las autoridades monárquicas como para los lonkos, la prioridad consistía en suprimir sus conductas transgresoras. La ambigüedad jurídica, con sus múltiples intersticios y vacíos, debía ser abolida; en su lugar, se debían implantar normas claras que hicieran posible una modalidad de vida civil más "ordenada", en "rejimiento y policía". Desde esa perspectiva, las autoridades monárquicas dieron un paso innovador al incorporar el liderazgo mapuche en el diseño de las políticas dirigidas a controlar a los sujetos mestizos insumisos y, de ese modo, extinguir los focos de desorden que debilitaban el sistema social a través de los extensos territorios fronterizos. Los lonkos respondieron positivamente a ese llamado -si es que no fueron ellos mismos sus gestores- y desplegaron su autoridad para conseguir que se materializara el viejo sueño de la paz.

\section{La política de parlamentos y el cogobierno fronterizo}

Desde fines del siglo XVI, coincidiendo con el arribo de la orden jesuita a la frontera del Bío-Bío, y una vez que se reconoció el poder militar de la sociedad

${ }^{21}$ Claudia Arancibia y otros, La pena de muerte en Chile colonial (Santiago: RIL, 2004). 
mapuche, las autoridades de Chile implementaron un proceso de negociación con los habitantes de la Araucania dirigido a pacificar los territorios por medio del pacto. Ese fue el origen de los parlamentos fronterizos ${ }^{22}$. Este fenómeno, inédito en el resto del continente, pronto dio sus frutos apagando el rumor bélico y poniendo en su lugar el pintoresco y masivo sistema de coexistencia que tanto llamó la atención de los viajeros y observadores de los siglos siguientes. Su objetivo, más que de control o de dominación imperial sobre los mapuches, como ha sostenido erróneamente Guillaume Boccara, fue de consolidación territorial, de ordenamiento de las relaciones de intercambio y de periódica ratificación del pacto de gobernabilidad que subyacía en la base misma de la vida fronteriza ${ }^{23}$. Por sobre todo, esta política presuponía la ausencia de hegemonías, eliminaba el elemento de superioridad que se arrogaron los españoles en otros lugares y reconocía el señorío de los lonkos como príncipes naturales en sus respectivas comunidades. Del diálogo, facilitado por los lenguaraces y los capitanes de amigos, pronto se hizo evidente que la gestación de la paz dependía de la voluntad política compartida por las autoridades de ambas sociedades. Su máxima expresión, como fruto del consenso y la negociación, fueron los tratados de paz suscritos entre ambas naciones $^{24}$. Las capitulaciones que componían estos tratados fueron el fruto de las largas discusiones que los españoles mantenían durante las juntas de guerra presididas por el gobernador del reino y que los lonkos realizaban en numerosas parlas (coyan) con sus respectivas comunidades, que concluían en las juntas generales (butacoyan) con la representación de los cuatro butalmapus. En total, durante el siglo XVIII, en la frontera del río Bío-Bío se celebraron más de 18 reuniones generales, con miles de asistentes, y sobre un centenar de congresos de menor rango o de naturaleza regional.

Como una forma de enfatizar la naturaleza pública de estas reuniones, los participantes en los parlamentos actuaban de acuerdo con un estricto protocolo. Los lonkos, estipulaba un testimonio del ceremonial:

\footnotetext{
${ }^{22}$ Luz M. Méndez, "La organización de los parlamentos de indios durante el siglo XVIII", en Relaciones Fronterizas en la Araucania, S. Villalobos y otros (Santiago: Universidad Católica de Chile, 1982); Guillaume Boccara, "Dispositivos de poder en la sociedad colonial-fronteriza chilena del siglo XVI al siglo XVIII", en Del discurso colonial al proindigenismo. Ensayos de Historia Latinoamericana, edit. Jorge Pinto R. (Temuco: Universidad de la Frontera, 1996).

${ }^{23}$ Guillaume Boccara, "El poder creador: tipos de poder y estrategias de sujeción en la frontera sur de Chile en la época colonial", Anuario de Estudios Americanos (Sevilla), 56 (1999): 88.

${ }^{24}$ Leonardo León y Hugo Contreras, "Documentos para la historia mapuche. Actas y tratados de parlamentos", manuscrito (Santiago: Universidad de Chile, 2003); Abelardo Levaggi, Paz en la frontera (Buenos Aires: Universidad del Museo Social Argentino, 2000).
} 
[...] entregan todos sus Bastones de que se hace un atado en el cual se coloca también el del Governador de la Frontera, y Señor Obispo más elevados, y el del Señor Capitan General superior a todos, y se pone en medio de la Ramada sosteniéndolos dos Mozetones Yndios $[\ldots]^{25}$.

El gobernador de Chile, máximo representante del monarca español en la región, era el primero en dirigir la palabra a la asamblea, luego que los jinetes mapuches celebraran sus cabalgatas y chivateos en torno al sitio para apaciguar los espíritus y las machis (chamanes) consagraran el lugar con sus ceremoniales ${ }^{26}$. El ritual de los parlamentos incluía la respuesta de la jefatura tribal a las propuestas del gobernador; si bien estas ya habían sido discutidas en las reuniones preliminares, el ejercicio que tenía lugar durante el parlamento era su legitimación pública.

Durante el período colonial hispano los parlamentos no tuvieron sólo un objetivo, pues se registró una transformación de las intenciones políticas que subyacían a estos congresos; pero siempre su designio fue transformar la frontera en un espacio de convivencia. Así, desde Negrete, en 1726, se observó la sistemática reiteración de un pacto colonial que en la práctica significó la consolidación de un efectivo sistema de coexistencia pacífica. La paz, sin embargo, no fue nunca duradera ni universal. Uno de los factores que impedía su consolidación fue la existencia de espacios controlados por los afuerinos, quienes, con su insubordinación, latrocinios y atropellos socavaban la gestión de las autoridades. Por tal motivo, la aparición de esos intersticios de malestar en medio de la paz se convirtió paulatinamente en uno de los problemas más significativos del proyecto hispano-mapuche. Esta tarea no fue un hito antojadizo en la agitada historia regional, sino que adquirió el perfil de un proyecto conjunto que acogió bajo su alero las expectativas e intereses de ambos mundos, pues desde el momento en que los afuerinos fueran percibidos como la principal amenaza contra el sistema de convivencia, la construcción del orden en las regiones fronterizas pasó a ser una tarea compartida. De lo que se trataba era de instaurar firmemente ya sea el admapu o el derecho monárquico para impedir que los afuerinos continuaran viviendo sin reconocer patria ni bandera, sentando un mal ejemplo para el resto de la sociedad mestiza.

Un momento culminante en el proceso de colaboración entre españoles y mapuches fue el parlamento general celebrado en Santiago el 15 de febrero de 1760. Esta reunión, la primera celebrada en la capital después de más de dos siglos de negociaciones, tuvo lugar luego de que un grueso contingente de jefes tribales llegó a la capital central con el objeto de entrevistarse con las principales autoridades del

25 "Ceremonial del Parlamento de Negrete de 1793", en "Acta del Parlamento de Negrete de 1793" [7 de marzo de 1793], Archivo Nacional, Claudio Gay 28, fols. 3-12.

${ }^{26}$ José Zavala, "L'envers de la 'frontière' du royaume du Chili. Le cas des traités de paix hispano-mapuches du XVIIIe siècle", Historie et Société de l'Amerique Latine (Nanterre), 7 (1998): 185-208. 
reino $^{27}$. La jefatura mapuche, representada por 32 lonkos, fue recibida por las máximas autoridades del reino con la pompa y ceremonial que se otorgaría a los representantes de una nación extranjera. De acuerdo con el informe remitido a Madrid, las causas de esta extraordinaria reunión debían buscarse en el amago de rebelión protagonizado por algunas tribus del sur a fines de 1759. En respuesta a esta potencial crisis militar, el gobernador Manuel de Amat organizó una expedición contra los rebeldes de río Bueno y ordenó la suspensión del comercio fronterizo en la región del río Bío-Bío. Estas medidas:

[...] Pusieron a los indios en breve tiempo en la mayor consternación y necesidad, de suerte que no pudiendo menos que confesar que, en las medidas que se habían tomado, se les hacía ver la dependencia que nunca conocieron $[\ldots]$.

La secuencia de estos acontecimientos habría sido favorable a los españoles, en tanto que habría obligado al liderazgo tribal a negociar un acuerdo de paz bajo las condiciones impuestas por los agentes del rey. Los mapuches, observaba el Acta del parlamento:

Resolvieron [de unánime consentimiento], doblar la cerviz que han mantenido erguida en más de doscientos años, y con una sumisión nunca vista, ni esperada de la Araucana soberbia, solicitaron con las mayores voces por medio de los padres misioneros y otras personas de autoridad, que se les otorgare venia a los cuatro Butalmapus (que son otros tantos cantones en que está dividida la tierra), para venir personalmente por sí o por sus emisarios hasta esta capital a rendir homenaje y hacer nuevos tratados que asegurasen, en lo futuro, una perpetua fidelidad.

¿Qué empujó a los jefes mapuches a viajar a la capital? Se menciona en los documentos el temor que les provocaban las amenazas de Amat, pero ello más bien redunda en el mito de que los españoles eran los únicos arquitectos de la política fronteriza. Por el contrario, se puede pensar que después de más de tres décadas de sosiego era necesario, para el liderazgo mapuche, recapitular las transformaciones que había experimentado el sistema de convivencia iniciado en 1726 y, mucho más importante aún, renovar el pacto de no agresión con su contrapartida monárquica. En otras palabras, la reunión de Santiago puede ser vista como el mejor reflejo de la participación de los mapuches en el diseño de la política de coexistencia que regía a la frontera.

27 "Acta del Parlamento de Santiago" [15 de febrero de 1760], Biblioteca Nacional (Santiago), Manuscritos Barros Arana, vol. 2, fols. 1000-1035. 
La lista de dignatarios que asistieron al parlamento de Santiago es bastante elocuente. En el caso mapuche, se registran los principales rehues que en esos momentos sustentaban el poder tribal, hecho reforzado por la participación de los lonkos Curiñamcu, Lepiñamcu, Ancalevi y Cheuqueant y Llancagueno, principales protagonistas de la historia fronteriza en las décadas siguientes. Por parte de los españoles, figuraron Amat, futuro virrey del Perú, el oidor Juan de Balmaceda, gobernador interino entre 1768 y 1770, el fiscal del reino José Perfecto de Salas, además de los ediles Diego Portales, Pedro de Lecaros y Manuel de Zañartu, figuras prominentes de la élite capitalina. Desde el punto de vista de la historia fronteriza, este parlamento no fue tan solo el primero en su género en la historia del país, sino que también fue emblemático en tanto allí se reunieron los principales protagonistas de la pacificación de la Araucania por el resto de la centuria.

La escena que se presenció en el centro de Santiago tuvo ribetes pintorescos pero nadie podía negar la solemnidad de la ocasión ni la importancia de lo que se trataba en la asamblea. Por primera vez, fueron los jefes mapuches los que tomaron la iniciativa para contribuir al ordenamiento de las relaciones fronterizas y al establecimiento de instituciones que consolidaran la presencia del Estado. Así lo hicieron notar sus voceros Pablo Liguenpichum y Gabriel Ancalevi.

[...] y puestos en pié, siendo preguntados por medio del intérprete que era el asunto de su venida hasta esta ciudad, tomaron la palabra y después de muchos preámbulos y alegorías, que usan a estilo oriental, dijeron que lo que les había traído desde tan considerable distancia atravesando ríos, sufriendo calores y demás incomodidades de un tan largo y penoso camino, era solo desvanecer la falsa calumnia que se les atribuía, de haber pensado levantarse y romper la paz y fidelidad que profesaban al Rey Nuestro Señor y a esta Capitanía General, cuyo falso rumor no tenía más fundamento que el antojo de sus mal querientes, siendo así que en sus tierras no ocurría la menor novedad y que ellos las estaban poseyendo quieta y serenamente, siguiendo en esto los consejos de sus mayores $[\ldots]^{28}$.

Interrogados por el gobernador respecto de la franqueza de sus declaraciones y del genuino cumplimiento de los acuerdos firmados con sus antecesores, los voceros mapuches insistieron en declarar que los rumores de rebelión que remecieron al reino en los meses previos

[...] habían sido falsos testimonios que les había levantado la malignidad de algunos [...] [que] nunca se les pudo encontrar fundamento positivo $\mathrm{y}$ fueron absueltos, y dados por libres los que sindicaban cuatro embusteros maliciosos, y que aunque era creíble [que] en una multitud tan considerable

28 “Discurso de los caciques Liguenpichun y Ancalevi”, ibídem, fol. 1017. 
como las de sus mocetones y vasallos, no faltarían muchos malos y delincuentes que aspirasen a fomentar semejantes revoluciones, pero que no es razón que el crimen de unos pocos comprehenda a todos en la responsabilidad; y que así conociendo que entre ellos mismos existían algunos malhechores, ladrones y turbulentos, habían traído en esta ocasión tres de los más sobresalientes, que quedaban entregados en las plazas de la frontera para que los desterrase a Juan Fernández o les diese el castigo que merecían sus atrevimientos ${ }^{29}$.

¿Podía haber una mayor demostración de colaboración en la lucha contra los afuerinos que la entrega de estos tres hombres? La gestión pacificadora de los lonkos fue aún más lejos. Pedro Naguelcoyan, lonko de la Imperial, solicitó:

[...] que a fin de contribuir al exterminio de ladrones ociosos y delincuentes de su jurisdicción, se le nombrase por este Gobierno a Juan Buricoyan, Juez de Comisión, por ser indio de juicio y representación $[\ldots]^{30}$.

El nombramiento de un juez de comisión fue otro signo del nuevo sistema de colaboración política que se gestaba entre las autoridades españolas y los jefes mapuches. Años de intercambio y convivencia habían echado las bases para que el lenguaje de la diplomacia reemplazara el ruido de las armas. Para los españoles, sin embargo, la condición de la paz debía ser aún más amplia.

[...] que si se obligan a ser perpetuamente fieles, y leales vasallos, a construir iglesias en sus respectivas reducciones, a oír con amor y humildad a sus misioneros, y vivir cristianamente -les señaló el gobernador- les permitiría libre tráfico y comercio de especies lícitas y permitidas, y les trataría y les haría tratar como a vasallos del Rey, sin diferencia entre blancos, y de color, españoles e indios ${ }^{31}$.

En otras palabras, Amat demandó que los mapuches vivieran en "orden, policía y regimiento". En Santiago, los jefes tribales expresaron su acuerdo con esta propuesta, pero aún restaba por verse si en la frontera prosperarían dichos planes.

\section{Los factores del desgobierno}

\footnotetext{
${ }^{29}$ Ibídem, fol. 1018. (Resaltado del autor.)

${ }^{30}$ Ibídem, "Discurso de los caciques Payllamanque, Tipayante, Quaticura, Chuquiantu, Cuilipel, Ancatemu y Nahuelcoyan".

${ }^{31}$ Ibídem.
} 
Durante la década de 1760-1770, la política del colaboración entre españoles y mapuches se enfrentó a las dificultades que presentaba el sistema de vida fronterizo que había forjado, durante décadas, estructuras e instituciones que favorecían conductas desmandadas. Una de estas instancias fue la cada vez más creciente internación de productos prohibidos europeos - manufacturas, armas de fuego, vino y alcohol- a los territorios tribales. En efecto, una modalidad de comercio que se inició con el trueque de fruslerías y productos domésticos adquirió durante esos años una magnitud, periodicidad y valor que nadie imaginó originalmente. Se gestó, subrepticiamente y al margen de la ley, una economía fronteriza ${ }^{32}$. También aumentaron las oportunidades para que emergieran los abusos asociados con las actividades clandestinas. Como en toda economía controlada por mercachifles y buhoneros, las prohibiciones dictadas por las autoridades y los esfuerzos que hicieron los ulmenes para mantener esta actividad bajo su férula obstaculizaron la distribución de los productos pero no lograron eliminar la demanda ni mucho menos extirpar las redes por las cuales fluían manufacturas, licores y armas. Por ese motivo, las autoridades procuraron mantener abiertos los canales "legales" del comercio, estableciendo ferias, calendarios y modalidades vigiladas de intercambio y favoreciendo el dispositivo alternativo de distribución de agasajos y regalos durante los parlamentos. La introducción de estos y otros "bienes de lujo" se convirtió en un elemento infaltable en las tratativas diplomáticas, demostrando el interés que ponían los lonkos en tener acceso a productos que proporcionaban prestigio y robustecían la fama de sus poseedores. "El cacique Ayllapan", escribió el comandante de Nacimiento en 1772 , "me ha pedido encarecidamente le traiga Vuestra Señoría de regalo unos calzones de tripe nácar con su franja y un sombrero de vicuña con franja" ${ }^{33}$. Sin embargo, el masivo mercado mapuche no podía ser satisfecho con melindres. Por ese motivo, la instancia del comercio ilegal llevado a cabo por los afuerinos adquirió cada vez más fuerza, hasta llegar a configurarse como uno de los principales factores de inestabilidad fronteriza. Abusos, fraudes, pleitos y deudas impagas, robos, saqueos y masacres fueron la otra cara del trueque ilegal, con un efecto perturbador en las relaciones de paz y en el sistema de relaciones internas de la propia sociedad tribal.

Otro factor de desgobierno fue la creciente presencia de colonos "blancos" en las tierras tribales. Si bien no es posible establecer su número o distribución

${ }^{32}$ Leonardo León, Maloqueros y conchavadores en Araucania y las Pampas, 1700-1800 (Temuco: Universidad de la Frontera, 1991); Jorge Pinto, De la inclusión a la exclusión. La formación del Estado, la nación y el pueblo mapuche (Santiago: Universidad de Santiago de Chile, 2000), 34.

33 "Carta del comandante de la plaza de Nacimiento Baltazar Gómez al Maestre de Campo General" [Nacimiento, 29 de agosto de 1772], AN (Santiago), Varios, vol. 288, fol. 638v. Véase también "Salvador Cabrito al gobernador Antonio de Guill y Gonzaga" [Concepción, 26 de marzo de 1765], Biblioteca Nacional (Santiago), Manuscritos Barros Arana, vol. 2, pieza 57 , fols. $830-839$. 
geográfica, la continua mención que se hace en los documentos oficiales de "españoles" asentados en la Tierra (como se denominaba al país mapuche) deja ver que su impronta era significativa. Estos colonos, de vieja raigambre fronteriza, entraban al territorio tribal para desempeñarse como capataces y arrieros, arrendatarios de potreros y pastores de las manadas que "veraneaban" en los pastizales del sur; también se menciona a sujetos que desempeñaban las tareas de herreros, zapateros, carpinteros y, de modo creciente, joyeros y plateros. La articulación de las economías de estos "colonos blancos" con el sistema de producción tribal no solo representaba un impacto de modernidad y vinculación externa sino que también creaba lazos de mutua dependencia que lentamente se hacían imprescindibles. Así se desprende de la solicitud hecha por Juan Catricura durante el parlamento celebrado con el obispo de Concepción a mediados de febrero de 1767, cuando demandó que:

[...] se les diese licencia a los Españoles que vivían en Tucapel, para que fuesen a cosechar sus Chacras que habían dejado allí, y volver a vivir a aquellas sus Casas, que habían desamparado [...].

Pocos años más tarde, los jefes de la tribu wenteche (llanistas) manifestaron sus deseos de "que todos los españoles que vivían en estos lados de Bío-Bío, poblasen sus estancias, que no se les seguiría el menor perjuicio" 34 .

En la medida que las autoridades lograban ponerse de acuerdo para regular la vida cotidiana en las tierras fronterizas, la existencia de los afuerinos se hizo cada vez más incierta. Vinculados solo por lazos de amistad con algún lonko poderoso, sus vidas corrían peligro toda vez que surgían en el horizonte las partidas de milicianos o de jueces de comisión siguiendo sus huellas o intentando averiguar la verdad sobre su pasado. Sin embargo, para los afuerinos no regía el respeto a la sangre que imponía el parentesco, sino tan solo el más frágil código de la hospitalidad que se otorgaba al extranjero o huinca. Por eso mismo, nada impedía que fueran las primeras víctimas durante los momentos de crisis. Así ocurrió a principios de 1767, cuando en la reducción de Lleulleu los guerreros liquidaron a un español allí asentado.

El Cacique de Lleulleu Colonpillan dijo que a dicho Español lo tenía alojado en su casa; y que dejándolo durmiendo en ella se fue a beber a otra casa inmediata, y estando en dicha bebida le preguntaron los indios que allí estaban por el español que tenía en su casa; y habiéndoles respondido que quedaba durmiendo; sin decirle nada se fueron dos de ellos de Guenquileu

34 “Acta de la Junta de Renaico" [10 de octubre de 1771], AN (Santiago), Varios, vol. 288, fols. $81-135 \mathrm{v}$. 
con otro, y lo mataron, y cortaron la cabeza; y que el Cacique de Renhilgue, Millantavum, hizo echar el cuerpo en una Laguna $[\ldots]^{35}$.

Para el afuerino, olvidado por su propia sociedad, no había nadie que llorara su muerte ni una tumba en la cual podrirse. Su sino de hombre sin tierra, sin patria ni familia era implacable hasta el último día de su vida.

Otra instancia que mermaba la quietud pública fue el cautiverio de hombres, mujeres y niños, tanto españoles como mapuches, que llevaron a cabo en forma progresiva los maloqueros trasandinos ${ }^{36}$. Por su naturaleza accidental, las noticias relativas a los cautivos son esporádicas y casuales. Una buena fuente, sin embargo, son las declaraciones que se tomaron a los cautivos, quienes, después de ser liberados, fueron interrogados por las autoridades. Estas declaraciones, proporcionan una imagen de las complejas relaciones sociales que subyacían al acontecer fronterizo. Uno de estos informantes fue Simón Bejar, liberado en febrero de 1767, quien manifestó en su declaración que

[...] habiendo ido a las salinas de los peguenches [...] en compañía de otros muchos vecinos de la Isla de La Laja [...] por la mañana llegaron como doscientos guilliches y con ellos dos españoles de Buenos Ayres que no sabe su nombre de ellos, pero sabe que estos fueron apresados por dichos yndios en Buenos Ayres en edad mediana y que se han criado con los guilliches y el uno de ellos está casado con la hija de Ninconaguel, hermano del gobernador de dichos guilliches [...] acompañaban también a estos doscientos algunos yndios de los llanos que se hacían distinguibles por su traje, aunque todos venían con las caras teñidas, y entre ellos conoció el declarante a un yndio maqueguano llamado Francisco, que solía benir a trabajar a la ysla de La Laja; conoció también a dos yndios de Tayguen [¿Traiguén?], aunque no sabe sus nombres, pero los ha visto otras veces en su propia tierra y son de la parcialidad de Guentequeu; y otros que por su traje y cara demostraban ser de los llanos [...]. Item, declara que en aquel paraje había diez cautivas de Buenos Ayres y entre ellas una de edad

\footnotetext{
35 "Acta del Parlamento de Nacimiento con los caciques costinos" [Nacimiento, 13 de febrero de 1767], Archivo General de Indias -en adelante AGI- (Sevilla), Audiencia de Chile, leg. 257, fols. 286v-299.

${ }^{36}$ K. Jones, "La cautiva: An Argentine Solution to Labor Shortage in the Pampas", en Brazil and Rio de la Plata. Challenge and Response. An Anthology of Papers, Luis F. Clay Méndez y otros (Illinois: University of Pittsburg, 1983), 91-94; Carlos Mayo, "El cautiverio y sus funciones en una sociedad de fronteras: el caso de Buenos Aires, 1750-1815", Revista de Indias (Madrid), 45 (1985): 235-243; Susan Socolow, "Los cautivos españoles en las sociedades indígenas: el contacto cultural a través de la frontera argentina", Anuario de Estudios Históricos y Sociales (Tandil, Argentina), 2 (1987): 98-136.
} 
crecida que tenía con ella dos niños, al parecer sus hijos, de edad de diez a doze años y que no se le permitió al declarante hablar con ellos ${ }^{37}$.

Como se puede desprender de su testimonio, Bejar no fue un hombre ajeno al turbulento acaecer que le cogió en sus redes. Al igual que él, peones y gañanes de estancias, arrieros, y viajeros, negros y mujeres de todas las edades fueron los desgraciados pobladores que se encontraron súbitamente transformados en esclavos de los naturales. No obstante, el cautiverio solía también tener un saldo positivo:

Una vez reinsertado en la sociedad de la frontera, el cautivo podía sacar partido de su experiencia en los toldos, donde había adquirido una nueva destreza que le abría nuevos horizontes laborales ${ }^{38}$.

Entre estos nuevos oficios figuraba de modo prominente el de baqueano. No menos importante es el valioso rol que jugaron los cautivos como intérpretes o lenguaraces. En otras ocasiones, los cautivos se convirtieron en werquenes de los lonkos, especialmente cuando estos últimos despachaban cartas a las autoridades coloniales. Pero fue en la guerra donde los mestizos cautivos se transformaron en la mayor amenaza, pues terminaron incluso comandando las partidas maloqueras.

De todos los sujetos "españoles" que interferían con el desenvolvimiento de las relaciones pacíficas, los conchavadores de Penco y Maule fueron los más notorios. Estrechamente vinculados a los lonkos mapuches, ellos controlaban el vaivén cotidiano transmitiendo rumores que les dejaban como los arquitectos subterráneos de los quiebres que, de tiempo en tiempo, devastaban el escenario fronterizo. En 1767, durante el parlamento celebrado con los llanistas, el obispo Ángel Espiñerira culpó a estos sujetos de ser los agentes del desorden. Exhortándolos a mantenerse tranquilos en sus tierras, el obispo reafirmó ante los lonkos que ni en España, Lima ni Santiago se abrigaban planes de conquista contra los mapuches, "aunque algunos Conchavistas miserables de los de acá de la frontera les diesen motivo para pensar otra cosa" ${ }^{\text {39 }}$.

\footnotetext{
37 "Declaración de Simón Bejar ante el comandante de la plaza de Nacimiento Pablo de la Cruz y Contreras, sobre su cautiverio entre los huilliches" [Nacimiento 7 de febrero de 1767], en "Expediente sobre movimientos y pacificación de indios en la región austral del reino de Chile e intervención del obispo de Concepción en este asunto" [1767], AN (Santiago), Fondo Fernández Larraín, vol. 71, pieza $10^{\mathrm{a}}$.

${ }^{38}$ Mayo, Vivir en la frontera, 90.

39 "Acta del Parlamento de Nacimiento con los caciques llanistas" [Nacimiento, 25 de febrero de 1767], AGI, Audiencia de Chile, leg. 257, fols. 312v-328v.
} 
La región fronteriza se prestaba para que afloraran las intrigas, más todavía cuando aún persistían focos de conflictos, como las crónicas guerras internas entre los propios mapuches, hábilmente explotadas por los afuerinos con el objeto de mantener el estado de tensión que favorecía sus lances ${ }^{40}$. Indudablemente, la amenaza de desaparecer bajo la furia de linajes enemigos obligaba a las comunidades más débiles a establecer alianzas con los afuerinos o a buscar apoyo entre los españoles. Ese fue el caso de los pehuenches asentados en los altos del río Bío-Bío, que soportaban los continuos embates de llanistas, de huilliches y de sus propios congéneres de Lonquimay e Icalma. Expuestos a estos ataques, los pehuenches solicitaron, a principios de 1767 , permiso a las autoridades de Chillán para que se les permitiera instalarse de modo permanente en los faldeos cordilleranos occidentales. Alegando el derecho que tenían a recibir la protección del monarca, los pehuenches manifestaron que no "será justo [que ellos] anden descarriados sin tener adónde vivir, lo que no se persuaden permita Su Señoría". A cambio de instalarse de modo permanente en las nuevas tierras, los lonkos de la montaña ofrecieron a los españoles que "conservarán siempre su fidelidad y asimismo, que serán buenos guardias y soldados seguros del paso de Alico de esta cordillera, en donde está el valle que piden"41. Acuerdos de esta naturaleza, forjados por el liderazgo tribal y las autoridades hispanas, aceleraban su acercamiento al común objetivo común de eliminar los roces que empañaban la paz. Sin embargo, estos acuerdos surgían bajo la presión de coyunturas bélicas, motivo por el cual se podía dudar de su permanencia. En efecto, su validez era frágil en un territorio continuamente expuesto a las peripecias de los aventureros que de modo creciente pululaban por las tierras de nadie, atizando los conflictos para poder saquear, matar y esclavizar. De lo que sí no quedaba duda era de que en ambas sociedades se consolidaba la percepción de que los principales promotores de los desórdenes eran estos nuevos tipos humanos que arrastraban consigo las semillas de la insubordinación y cuya vida desordenada y licenciosa dejaba una indeleble huella en el paisaje.

A comienzos de la década de 1770, ya no fueron tan solo los ocasionales afuerinos buscavidas los principales protagonistas de esta historia de anarquía, sino que ella ya abarcaba incluso a los mismos españoles encargados de vigilar la campaña. Desertores y fugitivos, vagos y renegados comenzaban también a merodear por las villas y rehues sin discriminación. El jesuita Miguel de Olivares manifestaba de que en tanto se criaban "entre breñas y montañas sin letras ni enseñanza", eran

\footnotetext{
40 "Informe del comandante de la plaza de nacimiento Pablo de la Cruz y Contreras sobre la petición de paz de los caciques llanistas" [Nacimiento, 13 de abril de 1767], AN (Santiago), Capitanía General, vol. 634, fols. 9-10v.

41 "Acta de la Junta de Chillán de 1767 con los pehuenches de Daguegue" [Chillán, 7 de marzo de 1767], ibídem, vol. 643, fols. 1-29v.
} 
"arrogantes y altivos, sin querer dejarse sujetar ni dominar [...]"42. El aislamiento en que vivían, proseguía Olivares, se combinaban para que viviesen cometiendo "pecados deshonestos [...] adulterinos unos, otros incestuosos y de mucho escándalo".

\section{El Parlamento de Negrete de 1771}

A pesar de que no se ha investigado la intervención de los afuerinos en la guerra mapuche de 1769, es significativa la mención que se hace de ellos en los acuerdos forjados durante el parlamento de 1771. Se puede decir, sin exagerar, que esa reunión estuvo casi enteramente dedicada a "legislar" sobre este asunto. Bajo el principio general de que debían "ser amigos de nuestros amigos, y enemigos de nuestros enemigos", y aceptando el rechazo que habían manifestado reiteradamente contra el proyecto de fundación de "pueblos de indios" en la Araucania, el gobernador Francisco Xavier de Morales y el liderazgo mapuche se propusieron introducir una serie de disposiciones dirigidas a contener las intrigas que a sus ojos alentaban los turbulentos habitantes de la frontera. Situados en el paradigma del cogobierno fronterizo que había surgido en la década previa, los redactores del acta del parlamento elaboraron el contenido de las capitulaciones con un tono que oscilaba entre la acusación y la exigencia, pero que en la práctica, depositaba gran parte de la gestión ordenadora en manos de las autoridades tribales. Significativamente, respecto de la guerra, se responsabilizó a los afuerinos de los sucesos acaecidos.

Que para su mayor sosiego serán obligados á entregar en las Plazas más inmediatas a sus reducciones todos los españoles, mestizos, mulatos negros ó de cualesquiera condición y clase que se refugiasen a sus tierras huyendo del castigo merecido por sus delitos, $u$ arrastrados de su torpeza para vivir más licenciosamente: pues de lo contrario se faltaría á la Justicia y se privaría al público de la vindicta, y ejemplo en la corrección y castigo de los malos. Debiendo observar lo mismo con los desertores, y fugitivos del presidio de Valdivia, cuando los requiera su Gobernador, como lo cumplen todos los caciques de aquella jurisdicción. Reflexionando que hombres de tan perversas costumbres solo servirían de alborotar la tierra: continuarían los hurtos y no se respetarían las mujeres, hijas y parientes de los Indios. Y tal vez atizarían el fuego de rebelión con el soplo de sus chismes,

\footnotetext{
${ }^{42}$ Miguel de Olivares, "Breve noticia de la Provincia de Jesús de Chile, desde que los religiosos de ella entraron en este reino, que fue el año 1593, hasta los años presentes, 1736", en Colección de Historiadores y Documentos Relativos a la Historia Nacional (Santiago: Andrés Bello, 1874), 3: 248.
} 
exponiendo a un general incendio toda la Tierra, viéndola reducida á cenizas por el acogimiento de tan perjudiciales bandidos ${ }^{43}$.

Si esta primera capitulación procuraba impedir el continuo paso y residencia de mestizos en tierras mapuches, la segunda capitulación estableció una normativa similar en relación con los naturales asentados en Chile central que huían continuamente hacia la Araucania con el fin de evadir sus obligaciones tributarias o de trabajo en las encomiendas.

Que con el propio derecho, y por los mismos motivos deberán entregar y restituir a los Yanaconas que se pasaren á sus reducciones; pues el ser de Indios no los exime de nuestra obediencia ni deben reputarse por de otra clase que los demás Españoles. Prevaleciendo siempre el justo derecho que sobre ellos tiene la Iglesia, el Rey, y sus Ministros por su doctrina, por su nacimiento y domicilio. No siendo menos justo atender al clamor de las mujeres é hijos de muchos de estos que quedarían sin este expediente abandonados para siempre. Más de que no llevados de otros impulsos que los de su libertinaje, y relajadas costumbres, les ocasionarían a los indios los propios inconvenientes y perjuicios que los demás Españoles prófugos que deben entregar para su castigo.

Como se desprende de estos textos, el desplazamiento de los afuerinos a través de la frontera fue masivo, polifacético y cada vez más frecuente. Algunos lo hacían para escapar de la justicia mientras otros lo hacían para evadirse del control patronal; otros huían, quizá, de un mal amor o buscando labrar una nueva vida. Transgredir, vivir libres, gozar los cortos días de una existencia accidental, turbulenta y azarosa, escabullirse de las funestas tutelas patronales, eludir el presidio y arrancarse de los sermones eclesiásticos, eran algunas de las motivaciones que subyacían a las defecciones de los hombres que hicieron del "vivir andando" un verdadero oficio. Atrás quedaban los terratenientes con sus estancias vacías, los hijos huérfanos y las víctimas aún asombradas de la audacia de los forasteros y afuerinos; al frente, en el camino largo y serpenteante, emergía la incertidumbre y el temor que inspira lo desconocido. El aura de misterio que precedía los pasos de estos hombres se confundía con el respirar agitado de los fugitivos que hacían sus derroteros con la mirada clavada en el hombro, pretendiendo adivinar el propósito de aquellos que los perseguían. ¿Quién lograría desterrar esos modos de vida ancestrales que surgen cuando la autoridad es débil y los límites entre lo legal y lo ilegal son tenues? Así, a medida que se consolidaba la paz con los mapuches, la marea de renegados aumentaba infaliblemente,

43 "Junta General de Guerra convocada para tratar los puntos del próximo Parlamento", Negrete, 23 de febrero de 1771, Biblioteca Nacional, Manuscritos Medina, vol. 332, fols. 536-538. 
transformando a los territorios de Penco y La Laja en el escenario de un trasvasije perturbador de peones que evadían los sistemas de vigilancia. Se puede decir que esos peones eran amantes consuetudinarios de su libertad, que no rehuían el trabajo sino la disciplina que las élites procuraban implantar. Eran tipos que buscaban recrear las condiciones materiales de vida que los vieron nacer y que lentamente desaparecían bajo el ímpetu de la alianza política forjada entre lonkos y corregidores.

La disponibilidad de recursos, las redes de solidaridad y la posibilidad de vivir como hombres libres que ofrecía el territorio fronterizo atraían poderosamente a los hombres y mujeres de espíritu más inquieto, brindándoles la oportunidad de participar en ese mundo de gente que compartía su existencia sin preguntar nombre ni apellidos. Por sobre todo, la frontera ofrecía bienes que todos codiciaban. De allí que el flujo de afuerinos hacia la Araucania tuviera su contrapartida en la continua migración de peones mapuches hacia las estancias criollas situadas al norte del río Bío-Bío. Así se desprende de la capitulación séptima del tratado.

Que los indios que quisieren pasar a trabajar en las haciendas, villas, y lugares de españoles lo podrán hacer por los pasos permitidos de Santa Bárbara, Purén, Nacimiento, Santa Juana, y San Pedro, presentando á sus respectivos Comandantes y a los Correxidores, y demás Justicias de los lugares á donde ocurrieren para que se enteren de su destino, y les administren Justicia en las causas que representaren, sin que unos, ni otros puedan llevar derechos por las expresadas diligencias (que deberán quedar sentadas en libros que á este fin deberán tener) ni por las que practicaren cuando se volviesen á sus Tierras; manifestándoles las especies que hubieren ganado con su trabajo, con el fin de evitar inconvenientes que de lo contrario se han seguido. Bien entendido que si los Indios fuesen aprehendidos por pasos y vados no permitidos, serán castigados con la pena que correspondiere: sin que los Caciques formen queja de su corrección, cuando pudiendo impunemente venir a nuestras Tierras por caminos directos, si los extravían dejan fundados indicios del mal fin con que se encaminan a nosotros ${ }^{44}$.

Sobre el punto de los trabajadores emigrantes, falta revisar los archivos de estancias para establecer la magnitud del movimiento estacional protagonizado por los mapuches que se enganchaban como peones y gañanes en las faenas agrícolas o que participaban en los rodeos de animales. Los datos disponibles apuntan a números significativos pero, por la naturaleza informal de estos movimientos, se insiste en no consignar en las cuentas a estos "trabajadores invisibles". Incidentalmente, existe un documento que describe un grupo de 21 pehuenches que

${ }^{44}$ Ibídem. fol. 539. 
trabajaron en las obras de Yumbel durante la segunda mitad del mes de febrero de $1770^{45}$. Luz María Méndez señala que en la construcción del fuerte de San Carlos de Purén trabajó un contingente de "14 a 17 indios por mes", mientras que en la corta de madera para fragatas realizada en la localidad de Talcamavida, en 1770, el número total de mapuches enganchados para las faenas subió a 116 individuos ${ }^{46}$. Holdenis Casanova, en su trabajo sobre la red de hechiceros mapuches asentados en Chillán, describe la existencia de una amplia trama de peones indígenas, algunos de los cuales provenían de las reducciones de "Tierra adentro": Malleco, Boroa y Chacaico. Estos peones, señala la autora, "se hallaban incorporados al servicio doméstico en las casas patronales y a las tareas agropecuarias en las haciendas y estancias fronterizas" $"$. En 1744, los curas reunidos en el sínodo obispal daban cuenta de una población de 4.000 personas, "indios, indias, sirvientes y otros fámulos" que trabajaban en Concepción. Se puede suponer que muchos de ellos eran peones migrantes. En Valdivia, mientras tanto, se registran durante el mismo período las categorías de "criados asalariados", "indios alquileros", "inquilinos" y el tradicional "peones", para referirse a un crecido contingente de naturales que prestaban servicios en la ciudad ${ }^{48}$. Sobre los efectos positivos que tenía el desplazamiento de los gañanes mapuches hacia las haciendas y obras estatales, el comandante de Yumbel señaló en 1770 que los peones reclutados en la construcción del fuerte "por leales al rey, se refugiaron entonces en Yumbel por no mezclarse con los revoltosos, que a la sazón maquinaban alzamiento" 49 .

La provisión de mano de obra desde la Araucania hacia las estancias criollas no fue exclusivamente un fenómeno laboral, sino también social, pues con los peones mapuches llegaban sus mujeres y parientes, además de sus temidas expresiones de sociabilidad. Los juegos de palin (chueca), nguillatunes (rogativas) y mingacos

45 "Lista de los yndios peguenches que se hallan trabajando en esta plaza de orden del Muy Ylustre Señor Capitán General de el día 6 de el presente mes" [Yumbel, 15 de febrero de 1770], AN (Santiago), Fondo Contaduría Mayor, $1^{\text {a }}$ serie, vol. 36, 1770-1790. Véase también "Carta del contador real Manuel José de Viale a los Oficiales Reales de Santiago" [Concepción, 18 de febrero de 1770], y "Carta del ex comandante de la plaza de Yumbel Domingo Albarez Ramírez a Lorenzo de Arrechea" [Concepción, 13 de diciembre de 1777], ibídem.

${ }^{46}$ Luz M. Méndez, "Trabajo indígena en la frontera araucana de Chile", Jahrbuch fur Geschichte Lateinamerikas (Colonia), 24 (1987): 219. Veáse Iván Inostroza, Historia de Concepción. Organización colonial y economía agraria, 1600-1650 (Temuco: Universidad de la Frontera, 1998), 31 y ss.

${ }^{47}$ Holdenis Casanova, Diablos, brujos y espiritus maléficos. Chillán, un proceso judicial del siglo XVIII (Temuco: Universidad de la Frontera, 1994), 69-70.

${ }^{48}$ Gabriel Guarda, "El servicio de las ciudades de Valdivia y Osorno, 1770-1780", Historia (Santiago), 16 (1980): 80.

49 "Lista de los yndios peguenches que se hallan trabajando en esta plaza [...]", ibídem. 
(fiestas comunitarias) que habitualmente enmarcaban las celebraciones de los peones reforzaban la faz mapuche del mestizaje. Según los españoles, la guerra mapuche de 1723 tuvo su origen en "un juego de chuecas" $"$. El sínodo de 1763 argumentó que el juego continuaba siendo practicando en los alrededores de las ciudades y que, "sin embargo de estar prohibido, no ha podido extirparse, antes sí regularmente se practica en parajes despoblados y en días de fiesta" ${ }^{51}$. En ese contexto, la Iglesia informó al gobernador Guill y Gonzaga que pesaba sobre los practicantes un decreto de excomunión. Según los prelados, el juego se celebraba durante tres días, "motivo para que la gente de ambos sexos, que concurre, pernocte en los campos", distrayendo a los feligreses y alentando el ausentismo laboral del peonaje. Sobre la persistencia del juego durante el resto de la centuria quedaron numerosos testimonios en los voluminosos expedientes judiciales.

En lo que anunciaba ser un plan de control de los expatriados, en el parlamento de 1771 se propuso también reglamentar el tránsito de los conchavadores que circulaban entre los pagos y rehues sin mayor sujeción a las autoridades monárquicas ni tribales.

Que habiendo mostrado la experiencia el gravísimo desorden que se sigue de la entrada de Españoles, ó de cualesquiera otros individuos, a tierras de Indios con el pretexto de conchavos, de que se originan perjudiciales diferencias, muertes y otros escándalos: que para cerrar la puerta a tanto daño, no se permitirá pase ningún español, ó de otra cualquier clase de la otra parte de nuestras Plazas situadas a orillas de Biobio, ni por los pasos de Cordillera a las habitaciones de los Infieles sin la expresa licencia de la Capitanía General, o del Maestre de Campo, dada por escrito, que deberán presentar a los comandantes de los fuertes por donde precisamente han de hacer la entrada, y serán obligados a su regreso á comparecer ante el mismo comandante, o ante otro, por donde correspondiera la salida. Y a los que contravinieren, y fueren aprehendidos por cualesquiera pasos [aunque no lleven especies de comercio] arrestados, y con escolta competente, se remitirán de Corregidor en Corregidor a la cárzel pública de Santiago para que por el tiempo que fuere el arbitrio del Superior Gobierno se destierren á alguno de los presidios del Reino a servir en las obras del rey, a ración y sin sueldo. $\mathrm{Y}$ en consecuencia de la tercera condición son obligados los

\footnotetext{
50 Jerónimo Pietas, "Noticia sobre las costumbres de los araucanos (1729)", en Historia física y política de Chile. Documentos, Claudio Gay (Paris, 1846), 1: 506.

51 "Sínodo diocesano que celebró el ilustrísimo señor doctor don Manuel de Alday y Aspée, obispo de Santiago de Chile" [1763], en Sínodos de Santiago de Chile de 1688 y 1763 , Bernardo Carrasco (Madrid: Consejo Superior de Investigaciones Científicas, 1983), 205.
} 
indios a entregar a los contraventores de este artículo siempre que fuesen requeridos por los jefes de la Frontera ${ }^{52}$.

La imposición de la autoridad sobre los conchavadores era un hecho inédito en la historia de las relaciones fronterizas, si bien existía consenso entre españoles y mapuches respecto de la necesidad de controlar el tráfico de mercaderías y de bienes que anualmente iban a parar en las comunidades del sur. Licencias y registro de la estadía de los conchavadores, además del reconocimiento de los territorios recorridos por los comerciantes, fueron algunos de los nuevos dispositivos de control que introducían las autoridades para ejercer control sobre las caravanas que entraban y salían de la Araucania. De ese modo se coronaba la política del colaboración, reforzando el poder que podían ejercer corregidores y lonkos sobre los "blancos" que cruzaban los ríos y vados fronterizos. Como parte de la colaboración que debían prestar las autoridades mapuches para hacer más eficaces las nuevas formas de vigilancia, se depositó en los jefes tribales la tarea de asegurar el paso de los viajeros y transeúntes españoles desde Concepción hacia Valdivia, particularmente de los portadores de correos y de los arrieros que transportaran víveres para el presidio sureño, impidiendo que fuesen víctimas de asaltos o robos por el camino. En reciprocidad, se incorporó además una serie de medidas que otorgaban las mismas condiciones de seguridad a los werquenes $y$ lonkos que desearan acudir a la capital del reino. La travesía de los representantes tribales debía hacerse portando un salvoconducto emitido por una autoridad fronteriza, el cual debían presentar a los corregidores de los territorios intermedios para evitar "cualesquiera perjuicios y vejaciones, tanto en la ida a la Capital, como en el regreso a sus tierras."

Otro cambio drástico que se registró en 1771 fue la eliminación del sistema de cuatro ferias anuales que reglamentaba, desde el Parlamento de Negrete de 1726, el flujo comercial entre Chile y la Araucania. Este sistema de ferias, que debía operar por un complicado procedimiento, fue reemplazado por una nueva modalidad que autorizaba a los mapuches a salir con sus efectos para la venta en las plazas militares, dando debida cuenta a los comandantes de "los géneros, y especies que hayan conchabado, y rescatado: sin que se les lleven derechos algunos, por combenir así al bien del Estado, y causa publica”. A renglón seguido, la misma capitulación ordenaba la confiscación de todos los bienes a los naturales que fuesen sorprendidos conchavando clandestinamente en sus tierras. Igual pena recaería sobre las mercancías de los comerciantes que se internaran ilegalmente hacia los rehues, los que además serían desterrados a unos de los presidios del reino.

52 "Junta General de Guerra convocada para tratar los puntos del próximo Parlamento" [Negrete, 23 de febrero de 1771], ibídem. 
Finalmente, reiterando diversas estipulaciones y prohibiciones previas, el tratado de 1771 se refirió al tema de la peligrosa internación de armas de fuego hacia las tierras mapuches. "Que para extirpar, y abolir tan fatales consecuencias se impondrá la pena de muerte al que se aprehendiere y justificare haberlas vendido á los Indios, ó bien introduciéndolas tierra adentro, o conchavándolas en las nuestras”. Esta medida fue anunciada por bando, para que toda la población del reino se enterara de su contenido. Igualmente drástica fue la prohibición de la venta de esclavos indígenas a la usanza, modalidad esclavista que amparaba toda clase de abusos contra los naturales capturados en las guerras. "Gozarán los indios señalaba explícitamente la capitulación- de su natural libertad; con declaración que el comprador de cualquiera Pieza perderá el valor de ella". Los mapuches que hubiesen sido vendidos por sus captores en las villas serían depositados con familias cristianas para su educación, mientras que los vendedores serían obligados a devolver el valor de la venta y a pagar una multa de igual monto. De ese modo se cortaba uno de los aspectos más lucrativos de las guerras intestinas que arrasaban a las tribus mapuches.

Uno de los detalles más significativos del Parlamento de Negrete de 1771 fue la ceremonia con que se cerró la reunión. Esa fue una puesta en escena del significativo nivel de colaboración que surgió entre españoles y mapuches en su lucha común contra los afuerinos.

Y terminados dichos Consejos [el lonko Catricura] se volvió al Señor Capitán General expresándole tenía concluido el Parlamento y que por las demostraciones de todos los cuatro Butalmapus quedaría la tierra en el mayor sosiego apagado el fuego, y que se prometía serían constantes y sólidas las paces que quedarían asentadas, prometiendo por su parte aconsejaría á todos los demás individuos que no han podido salir á este Campo por indisposición, y otros por falta de cabalgaduras. Su Señoría le significó el regocijo con que quedaría de las puras intenciones con que asegurarían la tranquilidad de toda la tierra, y les prometía en nombre del Rey tratarlos como vasallos de Su Majestad, hacerles Justicia y protegerlos en todo cuanto fuese de su alivio siempre que se mostrasen con el propio Corazón que al presente le habían manifestado.

Los acuerdos suscritos por las autoridades durante el Parlamento de Negrete contaban con el respaldo de las máximas autoridades del reino y de la Araucania, pero aún requerían de un proceso de legitimación que hiciera más universal y efectiva su ejecución. Tradicionalmente, el gobernador de Chile remitía las capitulaciones a España, las que eran analizadas y ratificadas por el monarca. En relación con las disposiciones más puntuales, la máxima autoridad del reino expedía instrucciones y bandos a corregidores y demás funcionarios subalternos ordenándoles la introducción de medidas pertinentes a los artículos concordados 
con los lonkos. Estos, por su parte, daban inicio a una serie de juntas -básicamente a nivel de agrupaciones sectoriales conformadas por los principales linajes de un distrito-para corroborar los acuerdos según el admapu y en presencia de toda la comunidad. Así ocurrió a principios de octubre de 1771, cuando los lonkos Cheuquelemu, Agustin Ligelemu, Ligpaigueque, y Francisco Ayllapan, y 26 caciques, capitanejos y mocetones se reunieron con el comisario de naciones Miguel Gómez para ratificar los tratados de Negrete. En dicha oportunidad Chequelemu llamó a sus seguidores a que cumplieran "en todo lo que prometieron en el Parlamento de Negrete" $" 53$. Una parla similar se sostuvo, a principios de febrero de 1772, con los pehuenches de los altos del río Bío-Bío, Queuco y Antuco, encabezados por su cacique gobernador Juan Leviant. Durante la reunión, el comisario de naciones expuso a los lonkos la frustración de las autoridades del reino porque "faltan a lo prometido, según propusieron en el Parlamento de Negrete y demás parlas que han tenido", atribuyendo a los afamados guerreros de la montaña los últimos actos de pillaje y saqueo que habían tenido lugar en esos días en los potreros de la Isla de La Laja. "Dice el cacique Levian que todo su deseo es el que la tierra se componga", escribió dando cuenta de la parla el comisario de naciones, que "se comprometen a todo lo que les mandasen como tales vasallos".

Para coronar el proceso de ratificación de los acuerdos de Negrete, los jefes tribales solicitaron viajar a la capital del reino. La autorización otorgada por los representantes del rey fue reforzada con la publicación de un instructivo que contenía las diversas medidas que debían tomarse para asegurar su tránsito. Entre los puntos más importantes, uno hecía relación con el tamaño de cada comitiva -un cacique y dos mocetones-, los alojamientos y comidas que debían dispensar a los viajeros, sus paraderos y campamentos; instalados en los extramuros o arrabales de las villas, se instruía a cada corregidor que evitara el contacto de los mapuches con extraños, "y sobre todo celará no se efectúe conchavo alguno con los yndios por Vino, ni otras especies ni que se les haga la menor extorsión cuando vienen bajo del salvoconducto del Soberano, y en la confianza de que se les ha de atender como á los demás vasallos" ${ }^{, 54}$. Para asegurar el buen trato de los naturales, se publicó otro Bando prohibiendo todo tipo de maltrato contra los viajeros, prometiendo castigos ejemplares a los trasgresores, "pues todos deben contribuir a que los yndios vengan seguros y experimenten el mejor trato, como se les tiene prometido y el Rey manda."

La frontera mapuche del siglo XVIII no fue una barrera infranqueable, sino que estuvo abierta a todo tipo de contactos e influencias. Lentamente, la vida cotidiana

\footnotetext{
53 “Acta de la Junta de Renaico" [10 de octubre de 1771], ibídem, fols. 81-135v.

54 "Instrucciones de la Capitanía General para el traslado de la comitiva de caciques que concurren al Parlamento de Santiago" [Santiago, 28 de octubre de 1771], ibídem, fol. 87.
} 
adquirió el ritmo que le impuso el mestizaje en combinación con la sociedad tribal; ambas, con el peso de sus sólidas tradiciones y su presencia demográficamente mayoritaria, influenciaron el desenvolvimiento del acaecer diario. ¿Quién podría negar que la sabiduría milenaria de los mapuches, con sus formas de organización social segmentadas y sus relaciones sociales basadas en los principios de reciprocidad, no había estructurado con éxito las relaciones fronterizas con los hispanos a partir de categorías opuestas a las de subordinación y de conquista? Aun cuando en estos momentos de la investigación es imposible reunir testimonios que permitan trazar la evolución de la mapuchización de la sociedad fronteriza, la ausencia de estos datos no significa que este hecho no haya tenido lugar. En realidad, cada aspecto de la historia regional demuestra que los acontecimientos políticos y económicos giraban, cada vez con mayor frecuencia, en torno a los ejes propuestos por los lonkos y aceptados por los representantes del rey ${ }^{55}$.

Más importante aún, tanto para el propósito de este estudio como para entender la evolución posterior de la región, la influencia de la sociedad tribal y el mestizaje en la sociedad regional también sirvieron de contexto para el surgimiento de los afuerinos. Estos, transformados en sujetos marginales, desafiaron los moldes implantados por españoles y mapuches, y alteraron continuamente los frágiles equilibrios que sostenían la coexistencia pacífica entre ambos mundos. Mucho más peligroso aún, los afuerinos comenzaron a ejercer una creciente influencia sobre el resto de la población, atrayéndola a sus modos de vida. La aculturación ya no era más el tránsito de español a mapuche o viceversa: el mestizaje ofrecía una estación intermedia, más fácil y accesible. De allí a transformarse en afuerinos solamente requería un pequeño esfuerzo de voluntad. La frontera crecía geográfica y socialmente, y se gestaban nuevos nichos de identidad.

La introducción de los reglamentos que normaban las relaciones fronterizas, que se registró durante el período 1760-1772, obedeció a una estrategia más amplia que tuvo por propósito aumentar el control de los movimientos de los afuerinos. Desde ese momento comenzaba a surgir un sistema de vigilancia más efectivo de caminos, vados de ríos y pasos cordilleranos, lo que eventualmente debía arrebatarles sus espacios. Era una forma indirecta de extirpar también sus formas de vida. Fundamentalmente, estas medidas reflejaban hasta qué punto el surgimiento de los afuerinos fue uno de los fundamentos de la original alianza política que forjaron los representantes del monarca con el liderazgo mapuche durante la segunda mitad del siglo ilustrado.

\footnotetext{
${ }^{55}$ Esta visión se opone a la propuesta formulada por Guillaume Boccara, "Organisation sociale, guerre de captation et ethnogenèse chez les reche-mapuche à l'époque coloniale", L'Homme, Revue Française D'anthropologie (París),150 (1999): 85-118; quien pretende visualizar un supuesto proceso de etnogénesis mapuche como resultado de las "multiples pressions exercées par les Espagnols [...]”, ibídem, 87, 101.
} 


\section{Bibliografía}

\section{Fuentes primarias}

Biblioteca Nacional, Santiago, Chile.

Archivo Nacional, Santiago, Chile.

Fuentes secundarias

"Acta de la Junta de Renaico" [10 de octubre de 1771]. En Sínodos de Santiago de Chile de 1688 y 1763. Madrid: Consejo Superior de Investigaciones Científicas, 1983.

Alcamán, Eugenio. "Los mapuche-huilliche del futahuillimapu septentrional: expansión colonial, guerras internas y alianzas políticas (1750-1792)". Revista de Historia Indígena (Santiago), 2 (1997): 29-75.

Arancibia, Claudia y otros. La pena de muerte en Chile colonial. Santiago: RIL Editores, 2004.

Araya, Alejandra. Ociosos, vagabundos y malentretenidos en Chile colonial. Santiago: Dirección de Bibliotecas, Archivos y Museos, 1999.

Boccara, Guillaume. "Dispositivos de poder en la sociedad colonial-fronteriza chilena del siglo XVI al siglo XVIII". En Del discurso colonial al proindigenismo. Ensayos de Historia Latinoamericana, edit. Jorge Pinto R. Temuco: Universidad de la Frontera, 1996.

"El poder creador: tipos de poder y estrategias de sujeción en la frontera sur de Chile en la época colonial". Anuario de Estudios Americanos (Sevilla), 56 (1999): 65-94.

. "Organisation sociale, guerre de captation et ethnogenèse chez les reche-mapuche à l'époque coloniale". L'Homme, Revue Française D'anthropologie (París), 150 (1999): 85-118.

Casanova, Holdenis. Diablos, brujos y espíritus maléficos. Chillán, un proceso judicial del siglo XVIII. Temuco: Universidad de la Frontera, 1994.

Cobos, María Teresa. "La institución del juez de campo durante el siglo XVIII". Revista de Estudios Histórico-Jurídicos (Valparaíso), 5 (1980): 85-165. 
Cavieres, E. "Sociedad rural y marginalidad social en Chile tradicional, 17501860". En Agricultura, trabajo y sociedad en América hispana, ed. Gonzalo Izquierdo, 91-105. Santiago: Universidad de Chile, 1989.

Cerda-Hegerl, Patricia. Fronteras del Sur. La región del Biobio y la Araucania chilena, 1604-1883. Temuco: Universidad de la Frontera, 1996.

Contreras, Hugo. "La soldadesca en la frontera mapuche del Bío-Bío durante el siglo XVI, 1600-1700”. Tesis de Maestría, Universidad de Chile, Santiago, 2001.

Góngora, Mario. "Vagabundaje y sociedad fronteriza en Chile (siglos XVI a XIX)". En Estudios de historia de las ideas y de historia social, 341-390. Valparaíso: Universitarias del Valparaíso, 1980.

Guarda, Gabriel. "El servicio de las ciudades de Valdivia y Osorno, 1770-1780". Historia (Santiago), 16 (1980): 67-177.

Inostroza, Iván. Historia de Concepción. Organización colonial y economía agraria, 1600-1650. Temuco: Universidad de la Frontera, 1998.

"Instrucciones de la Capitanía General para el traslado de la comitiva de caciques que concurren al Parlamento de Santiago" [Santiago, 28 de octubre de 1771]. En Sínodos de Santiago de Chile de 1688 y 1763. Madrid: Consejo Superior de Investigaciones Científicas, 1983.

Jiménez, Juan F. "Guerras intertribales, guerras coloniales y conservación del poder entre los peguenches de Malargue: la jefatura de AncánAmun (17791787)”. Manuscrito. Neuquén: Universidad del Comahue, 1997.

Jones, K. "La cautiva: An Argentine Solution to Labor Shortage in the Pampas". En Brazil and Rio de la Plata. Challenge and Response. An Anthology of Papers, Luis F. Clay Méndez y otros. Illinois: University of Pittsburg, 1983.

"Junta General de Guerra convocada para tratar los puntos del próximo Parlamento". [Negrete, 23 de febrero de 1771]. En Sínodos de Santiago de Chile de 1688 y 1763. Madrid: Consejo Superior de Investigaciones Científicas, 1983.

León, Leonardo. "Mestizos e insubordinación social en la frontera mapuche, 17001726”. Estudios Coloniales (Santiago), 2 (2002): 207-280. 
. "Evolución de la frontera pehuenche en La Laja y Bío-Bío: territorios, comercio y misiones, 1730-1760". Revista de Ciencias Sociales (Valparaíso), 44 (1999): 409-475.

"La herida me la dio en buena [...] El ordenamiento del espacio fronterizo mapuche, 1726-1760". Revista de Historia Social y de las Mentalidades (Santiago), 5 (2001): 129-166.

"La corona española y las guerras intestinas entre los indios de Araucania, Patagonia y las Pampas, 1760-1806". Nueva Historia (Londres), 5 (1982): 31-67.

. Apogeo y ocaso del toqui Francisco Ayllapangui de Malleco, 17691776. Santiago: Centro de Investigaciones Históricas Diego Barros Arana, 1999.

Los señores de la Cordillera y las Pampas: los pehuenches de Malalhue, 1770-1800. $2^{\mathrm{a}}$ ed. Santiago: Centro de Investigaciones Históricas Diego Barros Arana, 2005.

"Historia social de la frontera mapuche en Chile y el Río de la Plata, 1700-1800”. Manuscrito. Santiago: Universidad de Chile, 2005.

. Maloqueros y conchavadores en Araucania y las Pampas, 1700-1800. Temuco: Universidad de la Frontera, 1991.

y Hugo Contreras. "Documentos para la historia mapuche. Actas y tratados de parlamentos". Manuscrito. Santiago, Universidad de Chile, 2003.

Levaggi, Abelardo. Paz en la frontera. Buenos Aires: Universidad del Museo Social Argentino, 2000.

Lorenzo, Santiago. Origen de las ciudades chilenas. Las fundaciones del siglo XVIII. Santiago: Andrés Bello, 1983.

Mayo, Carlos. "El cautiverio y sus funciones en una sociedad de fronteras: el caso de Buenos Aires, 1750-1815”. Revista de Indias (Madrid), 45 (1985): 235243.

Mayo, Carlos, ed. Vivir en la frontera. La casa, la dieta, la pulpería, la escuela (1770-1870). Buenos Aires: Biblos, 2000. 
Méndez, Luz M. "La organización de los parlamentos de indios durante el siglo XVIII". En Relaciones Fronterizas en la Araucania, S. Villalobos y otros. Santiago: Universidad Católica de Chile, 1982.

"Trabajo indígena en la frontera araucana de Chile". Jahrbuch für Geschichte Lateinamerikas (Colonia), 24 (1987): 213-249.

Olivares, Miguel de. "Breve noticia de la Provincia de Jesús de Chile, desde que los religiosos de ella entraron en este reino, que fue el año 1593, hasta los años presentes, 1736". Colección de Historiadores y Documentos Relativos a la Historia Nacional. Santiago: Andrés Bello, 1874.

Pietas, Jerónimo. "Noticia sobre las costumbres de los araucanos, 1729". En Historia física y política de Chile. Documentos, Claudio Gay. París: s. ed., 1846.

Pinto, Jorge. De la inclusión a la exclusión. La formación del Estado, la nación y el pueblo mapuche. Santiago: Universidad de Santiago de Chile, 2000.

"Primer Sínodo Diocesano [que] celebró el Iltmo. Señor Doctor Don Pedro Felipe de Azúa e Iturgoyen, del Consejo de Su majestad, Obispo de esta Santa Iglesia de la Concepción de Chile. 12 de octubre de 1744". En "La defensa del indio en el sínodo del Obispo Azua de 1744", Carlos Oviedo Cavada. Historia (Santiago), 17 (1982): 281-354.

Salas, José Perfecto de. "Informe sobre el Reino de Chile, 1750". En Un letrado del siglo XVIII. El Doctor José Perfecto de Salas, Ricardo Donoso. 2 t. Buenos Aires, 1963.

Salazar, Gabriel. Labradores, peones y proletarios. Formación y crisis de la sociedad popular chilena. Santiago: Sur, 1985.

"Sínodo diocesano que celebró el ilustrísimo señor doctor don Manuel de Alday y Aspée, obispo de Santiago de Chile, 1763”. En Sínodos de Santiago de Chile de 1688 y 1763, Bernardo Carrasco. Madrid: Consejo Superior de Investigaciones Científicas, 1983.

Socolow, Susan. "Los cautivos españoles en las sociedades indígenas: el contacto cultural a través de la frontera argentina". Anuario de Estudios Histórico y Sociales (Tandil, Argentina), 2 (1987): 98-136. 
Villalobos, Sergio. "Tipos fronterizos en el ejército de Arauco". En Relaciones fronterizas en la Araucania, Sergio Villalobos y otros, 175-221. Santiago: Universidad Católica de Chile, 1982.

Vida fronteriza en la Araucania. El mito de la Guerra de Arauco. Santiago: Andrés Bello, 1995.

"Borbones y bárbaros. Centro y periferia en la reformulación de la política de España hacia los indígenas no sometidos". Anuario de Estudios HistóricoSociales (Tandil, Argentina), 13 (1998): 147-171.

Weber, David y Jane M. Rausch, eds. Where cultures meet. Frontiers in Latin American History. Washington: Scholarly Resources, 1994.

Zavala, José. 'L'envers de la 'frontière' du royaume du Chili. Le cas des traités de paix hispano-mapuches du XVIIIe siècle". En Historie et Société de l'Amerique Latine (Nanterre), 7 (1998): 185-208.

Fecha de recepción: 14 de febrero de 2006.

Fecha de aceptación: 14 de julio de 2006. 